\title{
Emphysema versus Chronic Bronchitis in COPD: Clinical and Radiologic Characteristics
}

\author{
Wafaa Ali Hassan*, Eman Abo-Elhamd \\ Chest and Radiology Departments, Assiut University, Assiut, Egypt \\ Email: "wafaagaallah@yahoo.com
}

Received 9 February 2014; revised 9 March 2014; accepted 15 March 2014

Copyright (C) 2014 by authors and Scientific Research Publishing Inc.

This work is licensed under the Creative Commons Attribution International License (CC BY). http://creativecommons.org/licenses/by/4.0/

(c) (i) Open Access

\begin{abstract}
Background and Objectives: In clinical practice, spirometry plays a key role in the diagnosis of chronic obstructive pulmonary disease (COPD), however, it provides no information about structural pulmonary abnormality. The aim of this study was to evaluate whether there is a relation between the clinical criteria and chest radiography or CT studies in differentiating chronic bronchitis from emphysema in COPD. Patients and methods: In a prospective study, data analysis on 165 COPD subjects who were enrolled between September, 2011 and December 2012 was completed. Data were collected including clinical characteristics of stable COPD, pulmonary function tests, chest X-ray and multidetector computerized tomography (MDCT) findings. Results: Emphysema was diagnosed in 90 (55\%) of 165 CT scans. The median emphysema score was 58 (range 48 - 72) and significantly correlated with lower $F E V_{1}$ values $(r=0.542, p=0.003)$. In chronic bronchitis, bronchial wall thickening was diagnosed approximately as often in chest radiography $(56 \%)$ as in CT (64\%) as a major finding. Body mass index (BMI), forced expiratory volume in the first second $\left(F E V_{1}\right)$, and diffusion capacity of the lung for carbon monoxide $\left(D_{\mathrm{L}, \mathrm{co}}\right)$ were significantly lower, whereas total lung capacity (TLC) was higher in patients with emphysema. Cardiovascular diseases and obstructive sleep apnea syndrome (OSAS) were more common in chronic bronchitis group. Conclusions: Chest radiography is a valuable, inexpensive means of diagnosing emphysema or bronchial wall thickening in chronic bronchitis. Emphysematous patients show a worse pulmonary function and a greater dyspnea. Greater comorbidity in chronic bronchitis may require specific treatment strategies in this subgroup.
\end{abstract}

\section{Keywords}

COPD, Chronic Bronchitis, Chest X-Ray, CT

\footnotetext{
*Corresponding author.
} 


\section{Introduction}

Chronic airflow limitation is thought to be resulted from the combination of two mechanisms: increased airway resistance due to narrowing of the small airways, and loss of lung elastic recoil due to emphysema. In clinical practice, spirometry plays a key role in the diagnosis of COPD and the assessment of disease severity and progression [1] [2]. However, it provides no information as to the presence or absence of a structural pulmonary abnormality [3]. Its recognitions are based on tests that reflect lung structure rather than function. The advent and proliferation of computed tomography initially allowed investigators to quantify changes in lung parenchymal structure in subjects with emphysema, and more recently attention has turned to the measurement of airway wall dimensions [4]. Unfortunately, while the lung density is relatively easy to quantify, reliable airway measurements have proven to be more difficult to obtain. However, recent advances in CT technology and new computer algorithms, and it is now hoped that many of the early issues surrounding airway measurements can be resolved [5]. The measurement of airway wall dimensions is important because it is well known that chronic airflow limitation can be caused by a combination of airway and parenchymal changes. The phenotypic expression of these different subtypes of COPD is vital because a therapy designed to modulate the inflammation in airways in chronic bronchitis may be contraindicated in subjects with the emphysema phenotype and vice versa. Therefore, these new imaging techniques are very likely to play a front-line role in the study of COPD and will, hopefully, allow clinicians to phenotype individuals, thereby personalizing their treatment [6]. The aim of this study was to evaluate whether there is a relation between the clinical criteria and chest radiography findings or CT studies in differentiating emphysema from chronic bronchitis COPD phenotypes.

\section{Patients and Methods}

In a prospective study, data analysis on 165 COPD subjects who were enrolled between September, 2011 and December 2012 was completed. Data were collected including demographic and clinical characteristics of stable COPD with no exacerbations in the last month.

COPD patients were diagnosed according to GOLD 2007 criteria (post-bronchodilator FEV1/FVC (after inhaling $400 \mathrm{mg}$ salbutamol) $<0.70$ ) with a significant smoking history ( $\geq 10$ pack years) [7]. Clinical historytaking, physical examination and the degree of dyspnea was assessed to all patients [8]. Lung function studies included measurement of FVC (forced vital capacity), FEV1, FEV1/FVC (before and after bronchodilator), TLC and single-breath diffusing capacity of the lung for carbon monoxide $\left(D_{\mathrm{L}, \mathrm{co}}\right)$. Measured $D_{\mathrm{L}, \mathrm{co}}$ were corrected for hemoglobin and carbon monoxide levels and expressed as a percentage of the predicted value [9]. To avoid misinterpretation of parenchymal changes, patients were excluded if they had any evidence of pneumonia, interstitial lung disease or pulmonary vascular disease. CT chest and posteroanterior and lateral chest radiography were performed for all patients. The study was approved by the Clinical Research Ethics Committee of Assiut University and all patients were informed of the characteristics and objectives of such study, giving their written consents for their participation.

\subsection{COPD Phenotypes: [10]}

Emphysema (at least one of the following criteria)

1) Pulmonary emphysema diagnosed by $C T$.

2) Diffusion test with transfer coefficient for carbon monoxide (TLCO/VA or KCO) values inferior to $80 \%$ and chest radiography suggesting emphysema, according to the criteria described by Miniati et al. [11].

Chronic bronchitis.

1) Habitual coughing and expectoration (chronic bronchitis criteria).

2) Diffusion test with TLCO/VA values superior to $80 \%$.

3) Absence of pulmonary emphysema demonstrated through imaging techniques, CT, or chest radiography, according to the previous criteria.

4) Absence of asthma antecedents.

\subsection{Chest X-Ray}

Postero-anterior chest radiographs were obtained in full inspiration on a standard system (Siemens, Germany) with the following parameters: $120 \mathrm{kV}, 2.5 \mathrm{mAs}$ and antiscatter grid with a 180-cm focus-detector distance. 
Storage-phosphor images were obtained using imaging plates (model CR MD4.0; Agfa). Posteroanterior and lateral chest radiography (99 digital and 55 analogue) were performed at a standard 2-m focus-to-detector (film) distance, with the patients upright and holding their breath at full inspiration. Chest radiographs were evaluated for the presence of thickening of bronchial walls (visible as tram tracks or ring shadows), the presence of linear or nodular opacities, ground glass opacity and emphysema. In evaluating emphysema, four radiographic criteria, originally introduced by Sutinen et al. [12], were used.

\subsection{Multidetector CT}

MDCT was performed using a Siemens scanner (Siemens, Erlangen, Germany). The lungs were scanned from the apex through the base at 1-cm intervals with the patient in the supine position and breath-holding at full inspiration, using 1-mm collimation and a high-frequency spatial reconstruction algorithm. Scans were viewed using a window level of -600 Hounsfield unit (HU) and width of $1500 \mathrm{HU}$, and were independently examined by two chest radiologists for the presence of areas of low attenuation and vascular disruption. Images were obtained in full inspiration using a $6460.75 \mathrm{~mm}$ slice collimation with a tube voltage of $120 \mathrm{kV}$. The reconstruction slice thickness was 3 - $5 \mathrm{~mm}$ and three reconstruction planes (axial, frontal and sagittal) were automatically obtained. The images were reconstructed in a high spatial resolution algorithm and displayed with a wide window setting at a width of $2000 \mathrm{HU}$ and a level of $2500 \mathrm{HU}$. During CT, 100 - $120 \mathrm{ml}$ of a 300/400 mg I contrast medium was administered intravenously at a rate of 2 - $3 \mathrm{ml} \mathrm{s}$ [12] with a power injector followed by a $30 \mathrm{ml}$ normal saline. The presence of linear or nodular opacities was noted. The presence of emphysema was classified as trace, mild, moderate or severe. The severity of emphysema was scored on a scale from 0 (no emphysema) to 100 using the picture-grading method [3] [13] adapted for CT. According to this method, a score of $\leq 5$ is consistent with trace emphysema, a score of 10 - 30 indicates mild emphysema, a score of >30 - 50 moderate emphysema and a score of $>50$ severe emphysema. The radiologist was unaware of the patients' clinical data. CT was used for comparison with chest radiographic results.

CT scans were analyzed for the presence of bronchial abnormalities, decreased lung attenuation, increased lung opacification and nodules. The presence of directly visible small airways with an internal diameter of $2 \mathrm{~mm}$ or a distance of $1 \mathrm{~cm}$ to the pleura was noted as a sign of thickening of small airways. CT criteria of Respiratory bronchiolitis-interstitial lung disease (RB-ILD) previously termed dirty lung in chronic bronchitis are variable (atelectasis, ground-glass opacity, emphysema, and linear and reticular abnormalities) [14]. The thickening of large bronchial walls in chronic bronchitis was described as published by Awadh et al. [15]. Vascular attenuation (thinning of pulmonary vessels and reduction in their number) and distortion (increased branching angle or straightening) were considered as signs of emphysema. Centrilobular emphysema was defined as round areas of low attenuation $1 \mathrm{~cm}$ in diameter within a homogeneous background of normal lung parenchyma. Panlobular emphysema was characterized as large and extensive areas of uniform low attenuation [16].

\subsection{Statistics}

We performed statistics by means of a linear regression model (Excel 2007; Microsoft Corp., Redmond, WA). Pearson's correlation test was performed to test significant correlations between the studied variables in both chest radiography and CT. Statistical significance was set at $\mathrm{p} \leq 0.05 .165$ patients were needed to reach an acceptable confidence level of $95 \%$ and statistical power of at least $80 \%$ (sample size) [17].

\section{Results}

Patients with emphysema (90 patients) did not differ from those with chronic bronchitis (75 patients) with regard to age, sex or, surprisingly, smoking history. By contrast, body mass index (BMI), FEV1, and $D_{\mathrm{L}, \mathrm{Co}}$ were significantly lower, whereas TLC was higher in patients with emphysema than in chronic bronchitis. Emphysemic patients showed significantly greater degree of their dypsnea than chronic bronchitis patients (Table 1). Arterial hypertension and stroke were insignificantly different in both types, whereas obstructive sleep apnea syndrome (OSAS) and arrhythmias were significantly higher in chronic bronchitis group $(p=0.000)$. Cardiovascular medications were more frequently used in patients with chronic bronchitic phenotype (0.03) (Table 2). Emphysema was diagnosed in 90 (55\%), whereas chronic bronchitis in 75 (45\%) of 165 CT scans. The median 
Table 1. Patient characteristics.

\begin{tabular}{|c|c|c|c|}
\hline & $\begin{array}{c}\text { Emphysema predominant } \\
\text { COPD }(\mathrm{n}=90)\end{array}$ & $\begin{array}{l}\text { Chronic bronchitis predominant } \\
\text { COPD }(\mathrm{n}=75)\end{array}$ & p-Value \\
\hline Male (n\&\%) & 78 (87\%) & $63(84 \%)$ & NS \\
\hline Age & $67 \pm 7.4$ & $62 \pm 9.3$ & NS \\
\hline Smoking index & $47 \pm 3$ & $49 \pm 4$ & NS \\
\hline BMI & $23 \pm 2.1$ & $32 \pm 3.4$ & 0.04 \\
\hline $\mathrm{FEV}_{1} \%$ pred & $40 \pm 10.2$ & $51 \pm 13.2$ & 0.03 \\
\hline FVC \% pred & $73 \pm 2.3$ & $68 \pm 4.4$ & NS \\
\hline $\mathrm{FEV}_{1} / \mathrm{FVC}$ & $48 \pm 4.2$ & $53 \pm 3.2$ & 0.05 \\
\hline$D_{\mathrm{L}, \mathrm{CO}} \%$ pred & $42 \pm 2.2$ & 70 & 0.000 \\
\hline TLC \% pred & $123 \pm 10$ & $89 \pm 14$ & 0.05 \\
\hline Dypsnea & & & 0.03 \\
\hline I & 10 & 18 & \\
\hline II & 25 & 17 & \\
\hline III & 26 & 15 & \\
\hline IV & 19 & 12 & \\
\hline V & 10 & 13 & \\
\hline
\end{tabular}

Table 2. Comorbid diseases and treatments associated with COPD.

\begin{tabular}{cccc}
\hline & $\begin{array}{c}\text { Emphysema-predominant } \\
\text { COPD }(\mathrm{n}=90)\end{array}$ & $\begin{array}{c}\text { Chronic bronchitis-predominant } \\
\text { COPD (n= } 75)\end{array}$ & p-Value \\
\hline OSAS & $1(1 \%)$ & $12(16 \%)$ & 0.000 \\
Hypertension & $18(20 \%)$ & $16(22 \%)$ & NS \\
Arrhythmias & $3(3.3 \%)$ & $8(11 \%)$ & 0.00 \\
Stroke & $2(2.2 \%)$ & $1(1.3 \%)$ & NS \\
ACEI & $10(11 \%)$ & $16(21 \%)$ & 0.03 \\
ARBs & $12(16 \%)$ & $6(8 \%)$ & 0.04 \\
\hline
\end{tabular}

ACEI: angiotensin converting enzyme inhibitors; ARBs: angiotensin receptor blockers.

emphysema score was 58 (range 48 - 72). Emphysema scores were significantly higher in patients with lower $\mathrm{FEV}_{1}$ values $(\mathrm{r}=0.542, \mathrm{p}=0.003)$. Emphysema was diagnosed consistently by chest $\mathrm{X}$-ray in 78 out of 90 cases (sensitivity 87\%). Chest X-ray failed to diagnose emphysema in 12 cases, all of them were mild (12.9 \pm 5.9 CT score). The rate of false-positive results was low (specificity 83\%) (Table 3).

In chronic bronchitis, bronchial wall thickening was diagnosed approximately as often in chest radiography (56\%) as in CT (64\%) as a major finding, whereas micronodular and reticular shadows were diagnosed in smaller percentages (12\% and $3 \%$ versus $60 \%$ and $42 \%$ respectively) (Table 4$)$. The most common findings in CT were thickening of bronchial walls (64\%), intralobular micronodules (61\%) and septal thickening (43\%). Ground-glass opacities were seen in only $4 \%$ of our patients (Table 5).

\section{Discussion}

Phenotype identification in COPD has been very varied. This aspect is really important, since the evidence collected during the last years confirms that, for the same FEV1, COPD patients can be very different from the 
Table 3. Sensitivity and specificity of chest X-ray versus MDCT in diagnosis of emphysema (90 patients).

\begin{tabular}{ccccc}
\hline Chest X-ray & True positive & Sensitivity & True negative & Specificity \\
\hline Emphysema & 78 & $87 \%$ & 60 & $83 \%$ \\
\hline
\end{tabular}

Table 4. MDCT findings in chronic bronchitis (75 patients).

\begin{tabular}{ccc}
\hline MDCT & Number & $\%$ \\
\hline Bronchial wall thickening & 48 & $64 \%$ \\
Intralobular micronodules & 45 & $60 \%$ \\
Septal thickening & 32 & $42 \%$ \\
Ground glass opacity & 3 & $4 \%$ \\
\hline
\end{tabular}

Table 5. Chest X-ray findings in chronic bronchitis (75 patients).

\begin{tabular}{ccc}
\hline Chest X-ray & Number & $\%$ \\
\hline Bronchial wall thickening & 42 & $56 \%$ \\
Micronodules & 9 & $12 \%$ \\
Reticular shadows & 2 & $3 \%$ \\
\hline
\end{tabular}

clinical, functional, imaging techniques, and evolution course point of view [18]. Although a degree of overlapping of the different lesions in airways (chronic bronchitis predominant) and pulmonary parenchyma (emphysema predominant) is high, it is clear that the presence of different injuries in the airways and pulmonary parenchyma, and the differences observed from the clinical point of view, make it reasonable to recover this approach. More recent work on CT demonstrated that it can help differentiate the COPD phenotype which is crucial for determining the appropriate management strategy [19].

In this study, patients who met the radiological CT criteria for emphysema had a significantly lower BMI, $\mathrm{FEV}_{1}$ and $D_{\mathrm{L}, \mathrm{CO}}$ than chronic bronchitis. Conversely, TLC was significantly higher in patients with emphysema. This lends support to the validity of the criteria used, which primarily reflect lung hyperinflation [20]. In addition, emphysemic patients experienced greater degree of dypsnea and expected more restriction of physical activity. The main characteristic of the group with chronic bronchitis is that, this is the type of patients showing a greater concentration of comorbidity, specially OSAS, and arrhythmias and more use of cardiovascular mediciations. This group presented a BMI significantly higher than emphysema. Therefore, obesity may constitute a bias explaining, at least partially, the differences in other co-morbidities or more use of cardiovascular medications [21]. The value of chest radiography for the assessment of emphysema has been a matter of contention since the 1960s [22]. In radiological-pathological correlation studies, the agreement between chest radiograph interpretation and morphological findings ranges from excellent to poor [23], depending upon the radiographic criteria used and the strictness applied by the investigators in matching their interpretation to the presence or absence of structural emphysema [24]. Even though CT is now regarded as the most accurate imaging technique for detecting emphysema, but has limitations of higher cost and substantial radiation exposure. Standard-dose MDCT of the thorax yields an effective radiation dose of $6-8 \mathrm{mSv}$ [25]. By contrast, digital chest radiography entails a much lower radiation burden than CT $(0.04-0.07 \mathrm{mSv}$ for posteroanterior and lateral chest radiography), is far less expensive and more available [26]. Being in a developing country, it is important to achieve the accurate diagnosis with lower costs. Therefore, the present study was undertaken, in addition to phenotyping of COPD, to reappraise chest radiography as a simple means of differentiating emphysema and chronic bronchitis. In emphysema, four radiographic criteria that had been validated against lung pathology [27] were used. Emphysema was diagnosed on chest radiographs in most patients with CT-confirmed disease (sensitivity 87\%). However, chest radiography failed to detect trace or mild emphysema that was apparent on CT. The rate of false-positive results was very low (specificity 83\%). The high results may be explained by the patients were 
studied under stable clinical conditions. The present results differ from those of Thurlbeck and Simon [28], who examined the value of chest radiography by comparing radiograph interpretation with that of inflation-fixed paper-mounted lung specimens. The radiographs were interpreted and the diagnosis of emphysema was made whenever characteristic vascular changes, termed arterial deficiency, were seen. This criterion permitted correct diagnosis in only $16 \%$ of the patients with mild-to-moderate emphysema and $42 \%$ of those with moderately severe-to-severe emphysema. It was also demonstrated that the sensitivity to chest $\mathrm{X}$-ray is not good, ranging from $24 \%$ to $80 \%$. In addition, there is considerable intra- and inter-observer variation regarding classical radiological signs [11]. Other authors suggest that conventional chest X-ray is not a reliable method for the diagnosis or quantification of emphysema [12]. In contrast to conventional chest X-ray, computed tomography (CT) has proven very sensitive and specific in the evaluation of emphysema [3].

In chronic bronchitis patients, bronchial wall thickening (64\%), intralobular micronodules were observed in $60 \%$, septal thickening in $42 \%$ and ground-glass attenuation was seen in $4 \%$; Holt et al. [29] found that the CT findings of RB-ILD are variable (atelectasis, ground-glass opacity, emphysema, and linear and reticular abnormalities). More recently, Park et al. [30] analyzed chest radiographs and CT scans of 21 smokers and exsmokers and noted major radiographic findings. CT findings were central (90\%) and peripheral (86\%) bronchial wall thickening, centrilobular nodules (71\%) and ground-glass opacities (67\%). Our sample showed a comparable frequency of centrilobular opacities (60\%), but a much lower frequency of ground-glass opacification (4\%). This might be explained by the technical differences in window level and width. The CT measurement of airway wall dimensions was important in the study of COPD because airway remodelling represents the major reason for airflow limitation [31] [32]. In our study, bronchial wall thickening was diagnosed approximately as often in chest radiography (56\%) as in CT (64\%) and — similar to other investigations [23] [30] as a major finding.

The pathological entity of smoke induced RB-ILD is also called "smokers' bronchiolitis" as it is seen almost exclusively in current or former smokers. While numerous publications have investigated the CT appearance of emphysematous changes of the lung parenchyma [23] [24] or alterations of the bronchial walls [30]-[32], less attention has been directed to the abnormalities of chest radiographs caused by chronic bronchitis or RB-ILD. Heyneman et al. [33] reported that the most common finding of RB-ILD on chest radiography is the thickening of the walls of the central or peripheral bronchi, which is seen in about $75 \%$ of the patients. Moon et al. [34] found a reticulonodular pattern in the chest radiographs of 5 out of 10 patients and ground-glass opacities in 2 out of 10 patients with histologically proven RB-ILD.

The use of CT modalities other than MDCT, including HRCT and three-dimensional CT-guided densitometry, MRI and volumetric assessment, represents an important advance in the investigation of patients with COPD, allowing better discrimination between the predominance of bronchitis or emphysema, as well as the identification of lesions in an earlier phase and the quantification of the extent of the disease [1] [3]. These imaging techniques are more expensive and the availability to use multiple radiological modalities is not available at our center due to limited financial resources.

In summary, the results of the present study indicate that chest radiography is a valuable, inexpensive means of diagnosing emphysema or bronchial wall thickening in chronic bronchitis. However, it is less sensitive than computed tomography for the detection of mild emphysema and less accurate for the evaluation of intralobular micronodules, septal thickening and ground glass opacities in chronic bronchitis. Limitations to this study are that the findings were not proven by a gold standard such as histological examination and the lack of comparison with other CT or MRI modalities

\section{References}

[1] Celli, B.R. and MacNee, W. (2004) Standards for the Diagnosis and Treatment of Patients with COPD: A Summary of the ATS/ERS Position Paper. European Respiratory Journal, 23, 932-943. http://dx.doi.org/10.1183/09031936.04.00014304

[2] Anon, C. (1959) Terminology, Definitions, and Classification of Chronic Pulmonary Emphysema and Related Conditions. Thorax, 14, 286-299. http://dx.doi.org/10.1136/thx.14.4.286

[3] Coxson, H.O. and Rogers, R.M. (2005) Quantitative Computed Tomography of Chronic Obstructive Pulmonary Disease. Academic Radiology, 12, 1457-1463. http://dx.doi.org/10.1016/j.acra.2005.08.013

[4] Thurlbeck, W.M. (1994) Emphysema Then and Now. Canadian Respiratory Journal, 1, 21-39.

[5] Thurlbeck, W.M., Dunnill, M.S., Hartung, W., Heard, B.E., Heppleston, A.G. and Ryder, R.C. (1970) A Comparison 
of Three Methods of Measuring Emphysema. Human Pathology, 1, 215-226. http://dx.doi.org/10.1016/S0046-8177(70)80035-1

[6] Kuwano, K., Matsuba, K., Ikeda, T., et al. (1990) The Diagnosis of Mild Emphysema. Correlation of Computed Tomography and Pathology Scores. The American Review of Respiratory Disease, 141, 169-178. http://dx.doi.org/10.1164/ajrccm/141.1.169

[7] Miravitlles, M., Calle, M. and Soler-Cataluña, J. (2012) Pulmonary Function and Clinical Phenotype in Chronic Obstructive Pulmonary Disease. American Journal of Respiratory and Critical Care Medicine, 185.

[8] Jones, P.W., Quirk, F.H., Baveystock, C.M. and Littlejohn, P. (1992) A Self-Complete Measure of Heath Status for Chronic Airflow Limitation. The St. George's Respiratory Questionnaire. The American Review of Respiratory Disease, 145, 1321-1327. http://dx.doi.org/10.1164/ajrccm/145.6.1321

[9] Cotes, J.E., Chinn, D.J., Quanier, P.H., Roca, J. and Yernault, J.C. (1993) Standardization of the Measurement of Transfer Factor (Diffusing Capacity). European Respiratory Journal, 6, 41-52. http://dx.doi.org/10.1183/09041950.041s1693

[10] Weatherall, M., Travers, J., Shirtcliffe, P.M., Marsh, S.E., Williams, M.V., Nowitz, M.R., et al. (2009) Distinct Clinical Phenotypes of Airways Disease Defined by Cluster Analysis. European Respiratory Journal, 34, 812-818.

[11] Miniati, M., Monti, S., Stolk, J., Mirarchi, G., Falaschi, F., Rabinovich, R., et al. (2008) Value of Chest Radiography in Phenotyping Chronic Obstructive Pulmonary Disease. European Respiratory Journal, 31, 509-915.

[12] Sutinen, S., Christoforidis, A.J., Klugh, G.A. and Pratt, P.C. (1965) Roentgenologic Criteria for the Recognition of Nonsymptomatic Pulmonary Emphysema. Correlation between roentGenologic Findings and Pulmonary Pathology. The American Review of Respiratory Disease, 91, 69-76.

[13] Nishimura, M., Makita, H., Nagai, K., et al. (2012) Annual Change in Pulmonary Function and Clinical Phenotype in Chronic Obstructive Pulmonary Disease. American Journal of Respiratory and Critical Care Medicine, 185, 44-52.

[14] Nakano, Y., Muro, S., Sakai, H., Hirai, T., Chin, K., Tsukino, M., et al. (2000) Computed Tomographic Measurements of Airway Dimensions and Emphysema in Smokers. Correlation with Lung Function. American Journal of Respiratory and Critical Care Medicine, 162, 1102-1108. http://dx.doi.org/10.1164/ajrccm.162.3.9907120

[15] Awadh, N., Müller, N.L., Park, C.S., Abboud, R.T. and FitzGerald, J.M. (1998) Airway Wall Thickness in Patients with near Fatal Asthma and Control Groups: Assessment with High Resolution Computed Tomographic Scanning. Thorax, 53, 248-253. http://dx.doi.org/10.1136/thx.53.4.248

[16] Saetta, M., Kim, W.D., Izquierdo, J.L., Ghezzo, H. and Cosio, M.G. (1994) Extent of Centrilobular and Panacinar Emphysema in Smokers’ Lungs: Pathological and Mechanical Implications. European Respiratory Journal, 7, 664671.

[17] Faul, F., Erdfelder, E., Buchner, A. and Lang, A.G. (2009) Statistical Power Analyses Using G*Power 3.1: Tests for Correlation and Regression Analyses. Behavior Research Methods, 41, 1149-1160. http://dx.doi.org/10.3758/BRM.41.4.1149

[18] Weatherall, M., Travers, J., Shirtcliffe, P.M., Marsh, S.E., Williams, M.V., Nowitz, M.R., et al. (2009) Distinct Clinical Phenotypes of Airways Disease Defined by Cluster Analysis. European Respiratory Journal, 34, 812-818.

[19] Washko, G.R. (2012) Rate of Decline in $\mathrm{FEV}_{1}$ : Is Emphysema the Culprit? American Journal of Respiratory and Critical Care Medicine, 185, 2-3. http://dx.doi.org/10.1164/rccm.201111-1938ED

[20] Garcia-Aymerich, J., Gómez, F.P., Benet, M., Farrero, E., Basaganã, X., Gayete, À., et al. (2011) PAC-COPD Study Group. Identification and Prospective Validation of Clinically Relevant Chronic Obstructive Pulmonary Disease (COPD) Subtypes. Thorax, 66, Article ID: 430e7.

[21] Fabbri, L.M., Beghe, B. and Agusti, A. (2011) Cardiovascular Mechanisms of Death in Severe COPD Exacerbation: Time to Think and Act beyond Guidelines. Thorax, 66, 745-747.

[22] Simon, G. (1978) Radiographic Appearance of the Chest in Emphysema. American Journal of Roentgenology, 130, 429-440. http://dx.doi.org/10.2214/ajr.130.3.429

[23] Sashidhar, K., Gulati, M., Gupta, D., Monga, S. and Suri, S. (2002) Emphysema in Heavy Smokers with Normal Chest Radiography: Detection and Quantification by HCRT. Acta Radiologica, 43, 60-65. http://dx.doi.org/10.1080/028418502127347457

[24] Miniati, M., Filippi, E., Falaschi, F., Carrozzi, L., Milne, E., Sostman, H. and Pistolesi, M. (1995) Radiologic Evaluation of Emphysema in Patients with Chronic Obstructive Pulmonary Disease. Chest Radiography versus High Resolution Computed Tomography. American Journal of Respiratory and Critical Care Medicine, 151, 1359-1367.

[25] Tack, D. and Gevenois, P.A. (2004) Radiation Dose in Computed Tomography of the Chest. In: Bankier, A. and Genevois, P.A., Eds., Imaging, Vol. 9, European Respiratory Society Monograph, Hanover, 39-50. http://dx.doi.org/10.1183/1025448x.00030003 
[26] Pratt, P.C. (1987) Role of Conventional Chest Radiography in Diagnosis and Exclusion of Emphysema. American Journal of Medicine, 82, 998-1006. http://dx.doi.org/10.1016/0002-9343(87)90163-X

[27] Remy-Jardin, M., Remy, J., Gosselin, B., Becette, V. and Edme, J.L. (1993) Lung Parenchymal Changes Secondary to Cigarette Smoking: Pathologic-CT Correlations. Radiology, 186, 643-651.

[28] Thurlbeck, W.M. and Simon, G. (1978) Radiographic Appearance of the Chest in Emphysema. American Journal of Roentgenology, 130, 429-440. http://dx.doi.org/10.2214/ajr.130.3.429

[29] Holt, R.M., Schmidt, R.A., Godwin, J.D. and Raghu, G. (1993) High Resolution CT in Respiratory Bronchiolitis-Associated Interstitial Lung Disease. Journal of Computer Assisted Tomography, 17, 46-50. http://dx.doi.org/10.1097/00004728-199301000-00007

[30] Park, J.S., Brown, K.K., Tuder, R.M., Hale, V.A., King Jr., T.E. and Lynch, D.A. (2002) Respiratory BronchiolitisAssociated Interstitial Lung Disease: Radiologic Features with Clinical and Pathologic Correlation. Journal of Computer Assisted Tomography, 26, 13-20. http://dx.doi.org/10.1097/00004728-200201000-00003

[31] DiMango, E.A., Lubetsky, H. and Austin, J.H. (2002) Assessment of Bronchial Wall Thickening on Posteroanterior Chest Radiographs in Acute Asthma. Journal of Asthma, 39, 255-261. http://dx.doi.org/10.1081/JAS-120002475

[32] Orlandi, I., Moroni, C., Camiciottoli, G., Bartolucci, M., Pistolesi, M., Villari, N. and Mascalchi, M. (2005) Chronic Obstructive Pulmonary Disease: Thin-Section CT Measurement of Airway Wall Thickness and Lung Attenuation. Radiology, 234, 604-610. http://dx.doi.org/10.1148/radiol.2342040013

[33] Heyneman, L.E., Ward, S., Lynch, D.A., Remy-Jardin, M., Johkoh, T. and Muller, N.L. (1999) Respiratory Bronchiolitis, Respiratory Bronchiolitis-Associated Interstitial Lung Disease, and Desquamative Interstitial Pneumonia: Different Entities or Part of the Spectrum of the Same Disease Process? American Journal of Roentgenology, 173, 1617-1622. http://dx.doi.org/10.2214/ajr.173.6.10584810

[34] Moon, J., du Bois, R.M., Colby, T.V., Hansell, D.M. and Nicholson, A.G. (1999) Clinical Significance of Respiratory Bronchiolitis on Open Lung Biopsy and Its Relationship to Smoking Related Interstitial Lung Disease. Thorax, 54, 1009-1014. http://dx.doi.org/10.1136/thx.54.11.1009 